\title{
APPLICATION OF MARINE CONTROL AND MONITORING SYSTEMS
}

\section{R.G.RANGASWAMY}

Research Scholar, AMET University, Chennai Tamil Nadu, India

\begin{abstract}
Expanded ship automatization levels prompt better usefulness and security, and also decreased expenses and team numbers. Incorporated into the introduction is as of late authorized impetus observing framework for quick watch vessels, dispersed fire and flooding assurance framework, send direction arrangement of a profound flexibility little vessel, maritime programmed degaussing structures, coordinated minimal effort mine countermeasures framework and organized hydrographic study and route framework for inland conduits. Vitality is essential to the world as a driver of the present day society. As per estimations were done by the International Energy Agency (IEA), the aggregate worldwide vitality utilization is around $17500 \mathrm{TW}$ h/yr. Before petroleum derivatives like coal, oil and flammable gas provided the most significant piece of this global usage, and they were far more significant than those of the sustainable power sources. In 2011, the creation of viable power source and worldwide vitality utilization expanded, despite the fact that sustainable power source was still substantially littler than petroleum derivatives. There are a few wellsprings of a viable power source, for example, hydro, wind, sunlight based, biofuel, and marine vitality. Be that as it may, since $71 \%$ of the world's surface is secured via ocean, marine vitality is a significant asset for thought, particularly when confronted with a perpetually developing vitality request. Aquatic dynamism incorporates seaward wind vitality, wave, tidal, tidal ebb and flows, warm, and saltiness slope vitality.
\end{abstract}

KEYWORDS: Marine Control, Monitoring Systems, Sustainable Power

Received: Oct 05, 2017; Accepted: Oct 25, 2017; Published: Jan 24, 2018; Paper Id.: IJMPERDFEB201892

\section{INTRODUCTION}

This paper gives a diagram of the marine control and checking frameworks created by the Control Engineering Department. Essential late ventures highlighting coordinated structures of marine gadgets are specified and quickly portrayed (Bediaga, I., \& et al. 2013). Extraordinary accentuation is given to the drive control, and checking framework dispatched not long ago (Hong, Y. Y., \& Bao, Y. Q. 2012). Noteworthy programming improvement has been incorporated into many cases, while a few undertakings performed framework mix (Zhang, X. P. 2012). Such control and checking frameworks are these days frequently amassed from mechanical business hardware, which has turned out to be sufficiently compelling and substantial for generally applications (Vukadin, P., \& et al. 1997 \& Blaabjerg, F., \& et al. 2006).

Essential frameworks to be automat zed on current boats are the route and direction framework, the impetus framework, the dynamic power framework, the fire and flooding assurance framework, helper frameworks, and different frameworks particular to some vessel classes. Low-temperature method for synthesis of $\mathrm{ZnS}$ quantum dots and its luminescence characterization studies are proposed by (Vukadin, P. 2001). These structures usually are commonly autonomous or softly interconnected; in spite of the fact that there exists a drive for more prominent subsystem mix on some propelled vessels and the mining and refinement of Antimicrobial Compounds from Marine Actinobacteria in these concepts presented in this paper (Chelvan, Y., \& et al. 2016). 
Favorable circumstances of higher automatization levels are various, including expanded usefulness and wellbeing and diminished expenses and group numbers. In this research paper described that the System of Ship Trajectory manage Using element Swarm Optimization is presented by (Sethuramalingam, T. K., \& Nagaraj, B. 2016). A monitoring sensor objects using mobile relay by path planning framework by (Pravallika, A., et al. 2017).

\section{MARINE ENERGY SYSTEMS OVERVIEW}

Marine vitality era frameworks vary primarily in the ways the vitality is caught and after that changed over into electrical life. Most other building obstructs in the era frameworks remain almost the same in the wake of being transformed into the electrical shape. The aggregate marine vitality that could be saddled is assessed at around $100000 \mathrm{TW}$ $\mathrm{h} / \mathrm{yr}$ which far surpasses the majority of the present human needs the world over. This makes it critical to comprehend the marine vitality era frameworks and the checking and control issues, which are talked about in this paper. The marine energy generation systems Monitoring and control framework are shown in Figure 1.

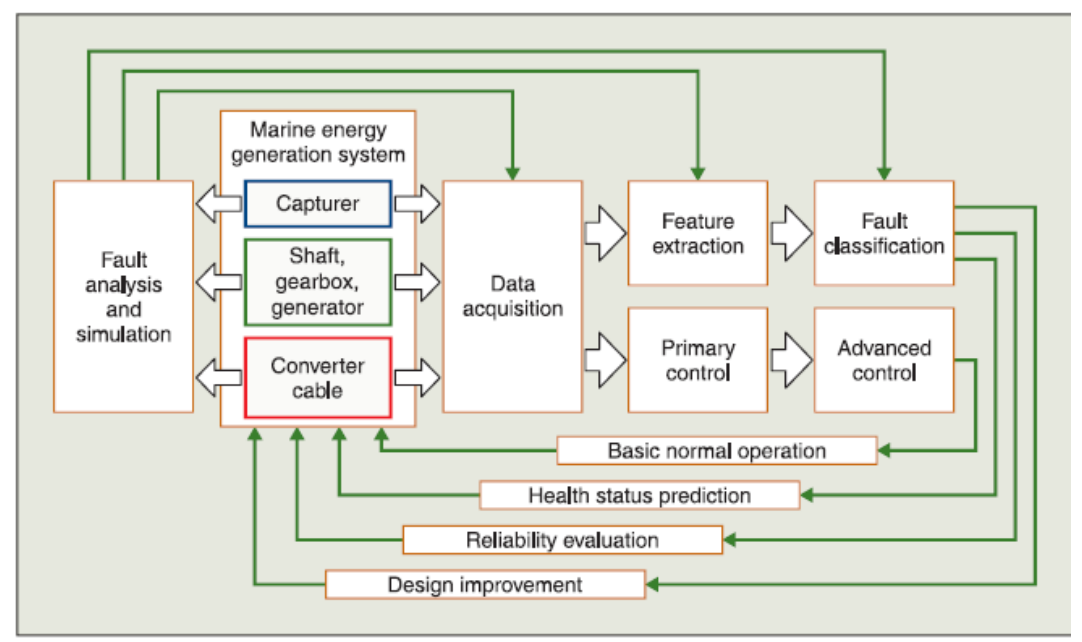

Figure 1: Monitoring and Control of a Marine Energy Generation Systems

Figure 1 demonstrates that an essential errand is to catch the source of vitality and it's checking to decide the turn on and turn off conditions, for example, the scope of wind speed, wave tallness and wave period, water stream speed, and different parameters, contingent upon the sort of marine vitality innovation utilized. The comparing wind-speed or water-speed sensors are employed to gauge the current capturer conditions before the tested information is used to change the operational mode or stop the marine vitality engrossing machine. At the same time, the working status of the capturer like the rotational speed and the capturer vibration flag can be measured to screen the operation.

\section{System Control and Monitor}

All marine vitality era frameworks will deliver electrical vitality which is adapted by current static power converters. Each power converter needs a straightforward modulator for driving it which is typically given Pulse Width Modulation (PWM). The marine energy generation systems Control structure framework is as shown in Figure 2. Be that as it may, a straightforward PWM control will for the most part not meet the quality and execution guidelines expected for an advanced marine vitality era framework. 


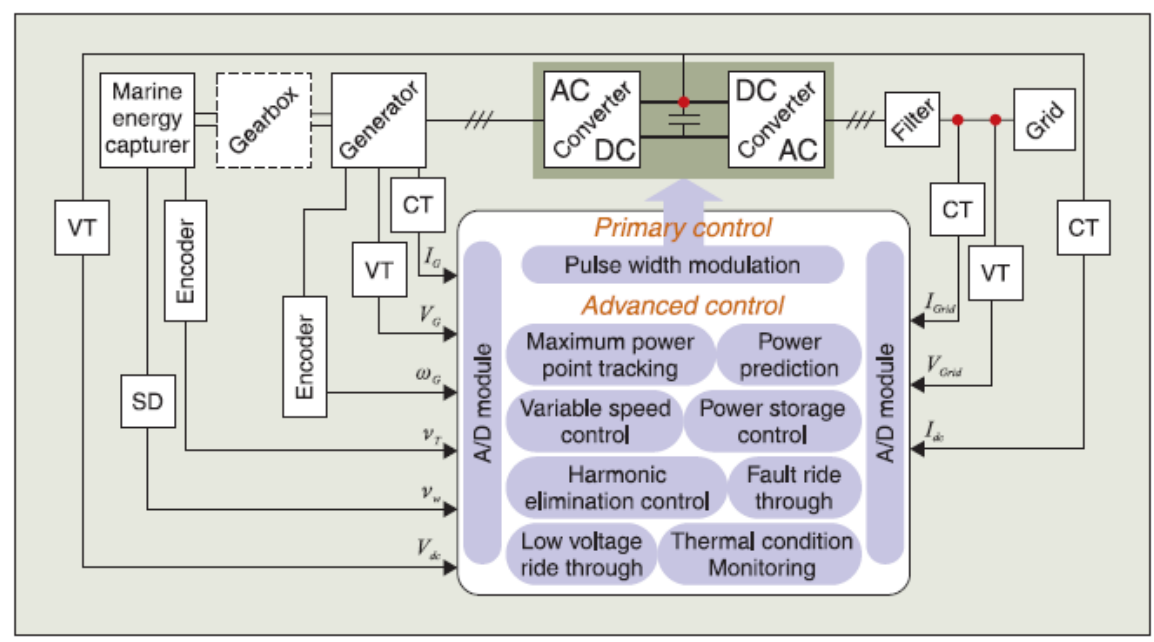

Figure 2: Control Structure of a Marine Energy Generation Systems

Other propelled control procedures must be connected as represented in the run of the mill setup appeared in Figure 2. To accomplish the most extreme caught vitality, a Maximum Power Point Tracking unit ought to be embraced, which should be possible by modifying the edge between the energy catching gadget and the wind, wave or water stream bearing, while likewise utilizing vitality stockpiling control for adjusting supply and load request. In the wake of being interconnected to the framework, helper control capacities like symphonious and unbalance remuneration can likewise be activated for enhancing the general supply quality. The most recent expansion would likely be low voltage and other blame ride-through control capacities, which have as of late been requested by utilities for keeping the marine vitality era framework running even under unusual network conditions.

\section{RESULTS AND DISCUSSIONS}

Offshore wind turbines are either settled to the ocean or buoy at the surface. Settled wind turbines are moored to the seabed to enhance essential steadiness. In any case, they are hard to work with the expansion of the separation from the shore where the wind is more bottomless. Hence, gliding wind turbines mounted on boats have been produced. The barges must be connected to the ocean bed by long steel links. This drifting wind turbine innovation is as yet experiencing tests to decide its reasonableness as the frameworks are regularly situated in deep water. Adjacent to their tying down contrasts, both sorts of seaward wind era frameworks share the same working standard, the turbine edges are pivoted by the wind. The relative potential of different marine energy sources is as shown in Figure 3.

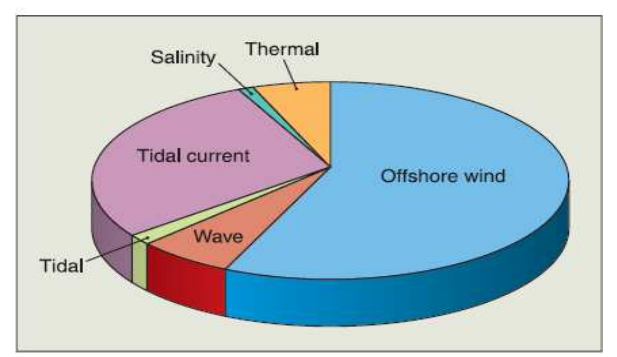

Figure 3: Relative Potentials of Different Marine Energy Sources

Vitality from the edges is then passed along the pivoting hub to a gearbox to alter the speed for driving the generator. The generator yield is the requested electrical vitality, which is along these lines prepared by power converters 
and ventured up to the coveted higher transmission voltage level and exchanged to the shore.

\section{CONCLUSIONS}

Marine vitality era frameworks have increased full consideration in the previous decade because a great deal of sustainable power source can be the outfit from the sea and transmitted for coastal use. The standards of marine vitality catch and additionally the advancements of the aquatic vitality transformation have been shown, and the improvement phases of the sorts of frameworks were condensed. To accomplish valuable and solid vitality yield, relating observing and control methodologies of the marine vitality change framework incorporate condition estimation and a progression of control techniques, for example, most extreme power following, variable speed control, symphonious concealment, et cetera. Down to earth, marine vitality frameworks confront many difficulties adrift which must be settled before significant commercialization can happen that will acquire a minimal effort of vitality. The challenges faced incorporate specialized obstacles like auxiliary soundness, erosion and transmission effectiveness, and also social barriers like the fundamental duty to secure marine conditions and keep up aquatic benthic biological systems driven by the practical improvement technique. With mechanical progression in the observing, indicative, control and assurance systems bit by bit joined, these obstacles are probably going to be settled instantly, enabling marine energies to be marketed and contribute substantially to the overall worldwide vitality generation.

\section{REFERENCES}

1. Bediaga, I., \& et al. (2013). The ball is bearing damage detection using traditional signal processing algorithms. IEEE Instrumentation \& Measurement Magazine, 16(2), 20-25.

2. Hong, Y. Y., \& Bao, Y. Q. (2012). FPGA implementation for real-time empirical mode decomposition. IEEE Transactions on Instrumentation and Measurement, 61(12), 3175-3184.

3. Zhang, X. P. (2012). Marine energy: The key to the development of sustainable energy supply [point of view]. Proceedings of the IEEE, 100(1), 3-5.

4. Vukadin, P., \& et al. (1997). High-performance cost efficient MCM system for COOP ships. In International Maritime Defence Exhibition \& Conference.

5. Blaabjerg, F., \& et al. (2006). Overview of control and grid synchronisation for distributed power generation systems. IEEE Transactions on industrial electronics, 53(5), 1398-1409.

6. Vukadin, P. (2001). An automated hydrographic system for inland waterway surveys. In $12^{\text {th }}$ International Symposium of the Hydrographic Society, 1-8.

7. Chelvan, Y., \& et al. (2016). Extraction and Purification of Antimicrobial Compounds from Marine Actinobacteria. Research Journal of Pharmacy and Technology, 9(4), 381-385.

8. N. K. Joshi \& V. K. Pravin, Analysis of the Impact of Variable and Non-Variable Inertia Torsional Vibration Characteristics of Marine Propulsion Plant Driven by Diesel Engine, International Journal of Mechanical and Production Engineering Research and Development (IJMPERD), Volume 4, Issue 1, January - February 2014, pp. 113-124

9. Sethuramalingam, T. K., \& Nagaraj, B. (2016). A Proposed System of Ship Trajectory Control Using Particle Swarm Optimization. Procedia Computer Science, 87, 294-299.

10. Pravallika, A., et al. (2017). Monitoring sensor objects using mobile relay by path planning framework. International Journal of MC Square Scientific Research, 9, (1), 288-294. 